\title{
DIALÉTICAS COLONIAIS \\ A construção do Estado e as transformaçóes da organização social indígena sul-americana
}

\section{Andrey Cordeiro Ferreira}

\section{Introdução}

Este artigo baseia-se numa pesquisa realizada entre os índios Terena, que têm quase todos seus territórios localizados na região do Pantanal do Mato Grosso do Sul. Nosso objetivo não é exatamente fazer uma descrição etnográfica ou histórica detalhada, mas, a partir da seleção de dados e problemas, apresentar uma interpretação específica para a etnografia do Chaco e algumas proposiçôes acerca da história indígena sul-americana em termos mais amplos. Esperamos que seja uma contribuição crítica à teoria antropológica sobre poder, política e organização social. Apresentamos algumas hipóteses sobre as relações dialéticas entre dois processos: o de construção do Estado nacional moderno no Brasil e o das transformações da organização social indígena sul-ame- ricana. Não seremos exaustivos na especificação das formas de Estado por conta das limitações impostas pela dimensão do artigo, mas temos em mente as diferenças entre formas de colonialismo e modelos de Estado. Interessa aqui indicar que o Estado moderno, seus fundamentos sociológicos e continuidades essenciais (ou seja, a construção do monopólio da força sobre o território e a institucionalização de uma hierarquia de classes atravessada por múltiplas formas de subalternidade, base de sustentação e de incidência da "soberania") remontam a alguns acontecimentos estratégicos, como as diversas formas de confrontação com as sociedades indígenas. A expressão "organização social-indígena sul-americana" não é usada como forma estrita de "generalização", mas indica que essa organização não se confunde com as fronteiras das futuras "nações", nem das futuras "etnias" contidas nessas naçôes. Trata-se de uma organização definida por processos sociais e ecológicos de larga escala, transfronteiriços, sendo sua negação 
um dos fundamentos da construção do Estado. Partindo de uma situação etnográfica específica, a dos índios do Chaco/Pantanal brasileiro, apresentamos hipóteses críticas alternativas às da etnologia evolucionista, estruturalista e estrutural-funcionalista sobre a "origem" do Estado. Enfatizamos aqui como as lógicas de segmentaridade e reciprocidade, descritas na etnologia, foram integradas por dialéticas coloniais e processos de dominação e resistência política.

Os índios aqui focalizados estão localizados há mais de três séculos numa região ecologicamente de alagaçōes e terras inundáveis, nas sub-bacias dos rios Miranda e Aquidauana, afluentes do rio Paraguai, nas chamadas "terras baixas" sul-americanas. O pantanal é entrecortado por diversas formaçōes montanhosas, como as serras da Bodoquena e de Maracaju, que ligam em termos ambientais Brasil, Paraguai e Bolívia, integrando os territórios numa unidade territorial e ecológica outrora (e ainda hoje em algumas regióes) conhecida como "Chaco". Esta mesma região guardou em diversos momentos (até fases muito avançadas do processo de conquista colonial) formas de comunicação com os Andes e com a região da floresta Amazônica. Assim, essa região constituiu-se não como um isolado geográfico e etnográfico, mas como um ponto no qual confluíam fluxos migratórios indígenas resultantes de deslocamentos forçados ou não, rotas coloniais sob formas de expediçōes, monçōes ou bandeiras e local de assentamento de determinadas sociedades.

Historicamente esta foi também uma região importante do ponto de vista da colonização, cenário de diversas políticas de proteção de fronteiras no século XIX e conflitos entre Estados pelo controle do território. Foi um dos palcos principais da Guerra do Paraguai, sendo a cidade de Miranda (principal local de nossa pesquisa) uma das primeiras a serem ocupadas militarmente pelas tropas paraguaias nos anos de 1860 . Ali, a articulação entre os Estados nacionais modernos e sociedades indígenas, bem como a dinâmica de seu conflito, assumiu dimensōes continentais e características que marcam a especificidade e a importância do sistema de relações interétnicas existente.

Por isso nos interessa discutir a problemática dos sistemas políticos, sua gênese histórica e confrontação. Resgatamos de forma crítica alguns debates da antropologia política clássica (teses estrutural-funcionalistas e estruturalistas), mas apresentando outra interpretação para a dinâmica interna das sociedades indígenas e formas de interdependência com as estruturas coloniais.

\section{Da antropologia das estruturas à antropologia dos processos históricos}

Podemos dizer que a antropologia política se formula sobre uma contradição interna, pois ela reconhece a alteridade de formas de organização (sistemas políticos) e, ao mesmo tempo, a enquadra dentro de determinada concepção filosófico-política, determinada teleologia que produz efeitos de exclusão de problemas históricos e etnológicos.

O tema central da antropologia política estrutural-funcionalista e de certos setores da etnologia sul-americana de influência estruturalista foi a afirmação e o reconhecimento da alteridade dos sistemas políticos baseados em lógicas próprias e específicas; em segundo lugar, o das condições de transformação ou passagem de um sistema político a outro (em certa terminologia, das chamadas sociedades sem-estado às sociedades estatais) ou então das condiçõos de preservação da alteridade dos sistemas políticos.

Ao mesmo tempo, tal enfoque formalista centrado na existência, na manutenção ou na transformação das diferenças não deu maior atenção aos processos de dominação que reconfiguravam os sistemas políticos e as próprias sociedades indígenas no movimento global de expansão da sociedade ocidental-capitalista. Nosso objetivo aqui é mostrar como na realidade tal abordagem formalista não consegue apreender o caráter eminentemente dialético das formações sociais coloniais, o grau e o sentido em que as organizaçōes sociais indígenas se transformaram diante do colonizador e, inversamente, como os próprios colonizadores tiveram de se transformar e moldar suas estratégias e instituições às condições criadas pelos sistemas políticos indígenas.

Devemos reconhecer que a principal virtude de estudos estrutural-funcionalistas, como os contidos em Sistemas politicos africanos, de Fortes e Evans-Pritchard, e estruturalistas, como no livro de Clastres A sociedade contra o Estado, é exatamente promover 
uma crítica profunda do etnocentrismo, tomando, num certo sentido, a dualidade criada pela antropologia evolucionista (que foi a primeira a perceber as especificidades da organização social indígena nas Américas). Mas, por outro lado, não podemos abdicar de expor os problemas aí presentes, pois tais abordagens terminam por produzir efeitos de exclusão, especialmente do conflito, da história e da ação (Cardoso de Oliveira, 1997; Fabian, 1983) que levam a outros impasses analíticos. Contraditoriamente, o movimento de reconhecimento da alteridade, que deveria ser uma afirmação da historicidade, converteu-se na sua negação. O principal problema é que as histórias e as culturas são desconectadas de seu contexto econômico e social e, sobretudo, das variaçôes e das contradições em suas práticas.

Podemos identificar dois campos de problemáticas: de um lado, as levantadas pela "teoria da descendência” que entendia que os sistemas políticos seriam organizados em sistemas de linhagens funcionalmente indiferenciados; de outro, as que partem da teoria da aliança e que orientam sua abordagem pela relação da constituição de uma região especificamente política nas sociedades indígenas e na sua relação com a reciprocidade, fundamento da própria diferenciação natureza/cultura.

No caso das abordagens funcionalistas faremos breves comentários, já que tratamos de maneira mais detalhada alhures (Ferreira, 2007). Os teóricos dos sistemas políticos africanos construíram um esquema analítico baseado em uma teoria específica do parentesco. Em termos gerais, sua formulação principal é que tais sistemas discriminavam dois grandes e distintos grupos: as sociedades estatais e as sociedades sem estado. No segundo grupo está presente o que denominaram "sistema de linhagem", que cumpre o papel da regulação das relações políticas. Assim, grupos de descendência unilateral estabelecem-se em unidades corporadas com funções políticas (Fortes e Evans-Pritchard, 1940, p. 6). O elemento fundamental aqui é a ideia de que o comportamento é comandado por normas estruturais que prescrevem a ação e o papel dos indivíduos dentro da estrutura social. A segmentação derivada das relações de descendência seria, assim, prescritiva no comportamento e levaria à formação de unidades políticas - unidades-base do próprio sistema de linhagem. Dentro do sistema de linhagem existe um princípio básico de fissão/fusão opondo os grupos de descendência corporados uns aos outros no nível local, mas que permite sua aliança num nível regional ou conforme a ampliação da escala territorial. A organização segmentar pressupóe uma lógica ou ciclos de fissão e fusão dentro das unidades políticas compostas por relacionamentos de parentesco. Dessa maneira, as alianças e os processos de cooperação política em situações de conflito se dariam de forma prioritária dentro de um sistema de relaçôes estruturalmente dado. ${ }^{1}$

A aplicação da dualidade de origem evolucionista (sociedades baseadas no sangue versus sociedades baseadas no território) seria recolocada de uma maneira distinta e principalmente com a preocupação de mostrar a coexistência histórica dos diferentes sistemas em vez de procurar entender como um evolui a partir do outro. A negação da evolução (ou da história conjectural) converteu-se numa negação de quase toda história para poder garantir a própria existência da especificidade dos sistemas políticos O "fechamento" seria o que garantiria a alteridade.

Uma diferenciação similar foi aplicada na análise dos sistemas sul-americanos por Pierre Clastres. Em suas proposições, existem elementos que são importantes por dois motivos. Em primeiro lugar, por sua construção teórica; em segundo, por sua interpretação específica para a região chaquenha dentro do quadro da América do Sul. Segundo o autor: "O que ocorre com os índios da América? [...] todas ou quase todas, são dirigidas por chefes e, característica decisiva digna de chamar a atenção, nenhum desses caciques possui poder" (Clastres, 2003, p. 27).

Mas essa afirmação categórica não é ingênua. $\mathrm{Na}$ realidade, ela se dá no quadro de uma crítica das categorias ocidentais, de como implicitamente, num julgamento que pretende ser meramente descritivo, há um julgamento de valor que se materializa na projeção da "ausência" das instituições ocidentais nas sociedades indígenas. No mesmo texto o autor afirma: "O exemplo evocado acima, das sociedades indígenas da América, ilustra perfeitamente, assim o cremos, a impossibilidade de falar de sociedades sem poder político. [...] Limitar-nos-emos a recusar a evidencia etnocentrista de que o limite do poder é a coerção, além ou aquém do qual nada mais haveria [...]" (Idem, p. 37). 
Essa formulação aponta então para uma conclusão que não deixa de ser importante: não existem sociedades sem poder, o que existe são sociedades com poder não coercitivo e sociedades com poder coercitivo (Idem, ibdem). Mas isso causa outro desdobramento: "o poder político como coerção é a marca das sociedades históricas, isto é, das sociedades que trazem em si a causa da inovação, da mudança, da historicidade” (Idem, p. 39). Ou seja, a conclusão última é que as sociedades sem poder "coercitivo" são as sociedades a-históricas, sociedades sem conflito, de "comunismo primitivo" (Idem, p. 40).

Em outro capítulo, "Troca e poder: filosofia da chefia indígena”, ele aprofunda essa teoria em dois sentidos: uma caracterização de "exceções" a esta regra e o desenvolvimento de uma explicação para a relação chefe-grupo, que seria a base da especificidade dos sistemas indígenas sul-americanos:

Dentre a enorme massa de tribos recenseadas na América do Sul, a autoridade da chefia só é explicitamente atestada em alguns grupos, tais como os Taino das Ilhas, os Caquetio, os Jirajara ou os Otomaque. Mas, convém assinalar que esses grupos, quase todos aruaques, estão localizados no noroeste da América do Sul, e que sua organização social apresenta uma clara estratificação em castas: só encontramos este último traço entre as tribos guaikuru e aruaque (guaná) do Chaco (Idem, p. 46).

Nesse sentido, podemos perceber dois movimentos: a afirmação de que é "a falta de estratificação social e de autoridade do poder que se deve reter como traço pertinente da organização política da maioria das sociedades indígenas [...]”. Apesar de não se deter sobre tais exceções, no caso dos grupos do Chaco, o autor sugere sutilmente que existem formas de estratificação que contrariam essa regra geral (Idem, ibidem) e nas exceções há ligações com os povos de tradição cultural andina, das terras altas, mais do que com os povos da floresta. Assim são exatamente os povos (Guaicuru e Guana) que figuram no centro de processos históricos fundamentais (colonização do Chaco) com consequências continentais que se apresentam como a "exceção" à regra. Voltaremos a tal questão adiante, pois ela é mais significativa do que a princípio possa parecer.

O fundamento dessa diferença estaria exatamente na "natureza" do poder e da chefia dos índios sul-americanos. A chefia seria definida por algumas características: a) o chefe é o fazedor de paz; b) deve sempre obedecer a regras de generosidade; c) deve ser um bom orador. Segundo o autor: "Com efeito, é notável constatar que essa trindade de predicados dom oratório, generosidade, poliginia, ligados à pessoa do líder, concerne aos mesmos elementos cuja troca e circulação constituem a sociedade como tal, e sancionam a passagem da natureza para cultura" (Idem, p. 55). Nesse momento, ele anuncia uma correlação fundamental, teórica e etnográfica: as sociedades sem poder coercitivo têm uma relação específica com os líderes, a qual expressa do ponto de vista político a mesma relação de ruptura entre natureza e cultura. A ideia de reciprocidade, lógica intrínseca do domínio da cultura, teria assim no sistema político indígena sul-americano uma manifestação específica de negatividade e controle.

É como se existisse uma filosofia subjacente a tal organização que levaria à negação da possibilidade de emergência do Estado em seu interior:

Uma relação original entre a região do poder e a essência do grupo se desvenda então aqui: o poder mantém uma relação privilegiada com os elementos cujo movimento recíproco funda a própria estrutura da sociedade; mas essa relação, negando-lhes um valor que é de troca ao nível de grupo, instaura a esfera da política não apenas como exterior à estrutura do grupo, mas bem mais como negando esta [...] (Idem, p. 59)

Clastres afirma que as sociedades indígenas se organizam contra o poder coercitivo. Este seria, assim, excluído da sociedade, já que é uma forma análoga à natureza, uma negação da "reciprocidade" que funda a cultura por meio das trocas. O "chefe" seria a negação dessa reciprocidade porque ele interrompe um fluxo de trocas ao concentrar mulheres, bens e palavras, por não existir a obrigação do "contra-dom". Mas, ao mesmo tempo, isso implica um processo de "externalização" do político, de maneira que, apesar dessas prerrogativas, e exatamente por 
elas, o chefe é esvaziado de autoridade efetiva. Dessa forma seria resolvido o problema da chefia e do político: dar ao chefe as prerrogativas que negam a reciprocidade e, ao realizar essa exclusão, neutralizam a possibilidade de um poder coercitivo do chefe sobre o grupo. Em seus fundamentos, a análise de Clastres entende que as sociedades indígenas sul-americanas tinham uma "sociedade contra o estado", que afirmavam uma filosofia do poder específica, baseada na negação do poder coercitivo - que por um instinto coletivo subjacente impedia o surgimento do Estado.

Chegamos a um ponto, pois, que nos é possível agregar as duas abordagens teóricas e fazer uma crítica aos fundamentos cognitivos de ambas, mas ao mesmo tempo retendo elementos de suas formulaçôes, ou melhor, a formulação de problemas etnológicos e como estes podem ser ressignificados. Em primeiro lugar, podemos dizer que existe um elemento comum, que é a ênfase sobre a antropologia das estruturas. No caso da teoria estrutural-funcionalista, há uma afirmação da estrutura como norma (os sistemas políticos são antes de tudo normas estruturais derivadas do parentesco que prescrevem comportamentos). No caso da interpretação estruturalista de Clastres, a ideia é de que as estruturas de pensamento subjacentes ao parentesco centrado na reciprocidade fazem emergir a especificidade dos sistemas políticos sul-americanos, de maneira que a oposição estrutural natureza/cultura se manifestaria no domínio político como a oposição poder coercitivo/poder não coercitivo.

Num caso se pretende ver como sistemas alternativos coexistem com o Estado, negando a evolução de um a outro; em outro, como no interior de um sistema de pensamento subjacente às sociedades indígenas o Estado é impedido de surgir em tais sociedades por suas estruturas de pensamento específicas. O problema é que por uma via ou por outra oblitera-se o fato histórico básico de que independentemente da coexistência sincrônica desses sistemas, ou de uma luta contra um Estado endogenamente gerado, o Estado efetivamente se impôs (tanto na América do Sul como na África) e, ao mesmo tempo, as sociedades indígenas não desapareceram. E hoje eles estão explicitamente articulados. A negação do caráter universalizante do Estado por meio do reconhecimento da "alteridade" acaba obscurecendo os processos históricos reais, as relaçôes contraditórias das sociedades indígenas com a formação desses Estados. A origem do Estado na América do Sul, ${ }^{2}$ dos Estados nacionais contemporâneos e sua relação dialética com os povos indígenas acaba sendo assim exteriorizada como objeto teórico.

Ambas as abordagens procedem a uma domesticação da historicidade, já que esta não é recusada, mas concebida como exterior às sociedades não ocidentais. A ideia de que as sociedades eram baseadas em grupos de parentesco de descendência unilinear em equilíbrio sistêmico, homólogos e fechados em si próprios, ou então por processos de troca/reciprocidade entre unidades cultural e igualmente fechadas, não permite uma compreensão satisfatória do processo de colonização, nem da organização social indígena nem das "variações" que elas podem apresentar.

Levantamos aqui duas ordens de questionamento, uma teórica e outra etnográfica. Em termos lógicos, se existia uma filosofia inerente à chefia indígena e à sua organização política no sentido de impedir o surgimento do Estado, generalizada nas terras baixas da América do Sul, se existia tal homogeneidade de sistemas e filosofias políticas, por que e como o Estado colonial conseguiu se formar e trazer vários grupos para sua aliança? Por que o Estado nacional moderno surgiu por meio do colonialismo exatamente naquele terreno que lhe seria menos favorável? Etnograficamente, por que grupos descartados como exceções - caso de Guaicuru e Guana do Chaco -, por apresentarem formas "hierárquicas", ofereceram, por sua vez, uma das mais sistemáticas e prolongadas resistências ao processo de colonização, criando grandes e seculares dificuldades para os Estados espanhol e português estabelecerem sua hegemonia?

No contexto da antropologia estrutural, a "superioridade técnica, militar e a violência e etc." seriam o recurso explicativo para manutenção do argumento teórico, com a consequente afirmação do insulamento indígena. Só que essa resposta gera um problema, pois retoma-se o discurso etnocêntrico e triunfalista que a princípio foi recusado. Ou então exterioriza-se a própria "variação" (Barth, 2000c), no caso, de grupos que teriam sociedades baseadas em forma de poder coercitivo e que historicamen- 
te apresentaram resistência aos Estados nacionais como temas não legítimos e, consequentemente, as variações das relações entre sociedades indígenas e o Estado moderno são marginalizadas

Para uma resposta mais satisfatória nesse sentido é preciso efetivamente desenvolver uma antropologia do decurso histórico. Os processos sociais são essencialmente temporais e dramáticos, implicam a um só tempo rupturas, transformações e conflitos que dão origem aos significados. ${ }^{3}$ Para isso é preciso, então, redefinir os conceitos de sociedade e pensar as formas de poder com base em outros parâmetros, que não da contraposição absoluta de alteridades. Isso se dá no quadro das tarefas apontadas por Eric Wolf (2009), que demonstra de forma categórica a necessidade de considerar a "etno-história" dos diversos grupos como parte de uma história global do desenvolvimento capitalista.

Vale dizer que a crítica teórico-epistemológica não implica em descartar certos problemas ou dinâmicas abordados pelas análises estruturalistas ou estrutural-funcionalistas. $\mathrm{Na}$ realidade, algumas formulações podem ser submetidas à reinterpretação. Em primeiro lugar, da teoria da descendência é importante a sua formulação acerca do princípio de fissão/fusão. Supõe-se nesse caso que as oposições sejam sempre do tipo interno versus externo (ao grupo de descendência) a partir de posiçôes estruturais; que as oposiçóes e as composiçōes se dariam sempre entre grupos com organização homóloga (unidades segmentares integrantes do sistema de linhagem). Quando nos desprendemos desses pressupostos, podemos considerar a organização segmentar um tipo de lógica político-territorial hegemônica que pode, inclusive, incorporar unidades de outros sistemas por meio de oposições/composições, já que os sistemas sociais são sistemas abertos (Barth, 2000b). Ao mesmo tempo, a distinção entre formas de poder (coercitivo ou não) pode possibilitar uma análise da história indígena e do processo de colonização de uma perspectiva dialética. Só que em vez de supor que cada forma de poder corresponde a um macrotipo de sociedade (estatais e "antiestatais", pela formulação de Clastres), devemos entendê-las como duas formas possíveis de interação e constituição das relaçôes políticas. Isso implica também em reconhecer que a reciprocidade não se inscreve apenas no âmbito do predomínio de uma forma de poder não coercitivo (e a implicação resultante da negação estrutural da reciprocidade para a consolidação deste poder) e nem se dá no interior de uma sociedade com estruturas homólogas e fechadas. Devemos assumir que, como processo temporal, a própria coerção pode gerar reciprocidade e vice-versa, e consequentemente um poder não coercitivo não implica necessariamente a negação ou a ruptura da reciprocidade, mas o deslocamento temporal mediado por escolhas, estratégias e fatores materiais.

Assim podemos considerar as noções de segmentaridade e reciprocidade no quadro de uma antropologia histórica do poder e da política, o que permite compreender as dinâmicas políticas e territoriais de formação do Estado moderno e a dialética da transformação da organização social indígena. $\mathrm{Na}$ realidade, entendemos que é exatamente a forma como a organização indígena se segmenta e as lógicas contraditórias de reciprocidade que estabelece dentro da situação colonial que explicam como se desenrolaram processos de dominação, resistência e colaboração que, ao mesmo tempo, levaram a obstruir o processo de colonização e explicar a consolidação do Estado nacional a partir de determinados processos históricos. É essa abordagem que desenvolvemos adiante.

\section{Segmentaridade e reciprocidade como processos temporais}

A região do $\mathrm{Chaco}^{4}$ é muito vasta e abrange contextos ecológicos relativamente diversos. Para o que nos interessa aqui, podemos dizer que ela era constituída por várias planícies inundáveis e por savanas entrecortadas por uma ampla e complexa bacia hidrográfica. Em termos territoriais, permitia uma conexão tanto com a região das florestas, na transição para Amazônia, como dos Andes. Essas condiçōes possibilitaram que determinados grupos indígenas, como os Guaicuru e os Paiaguá, desenvolvessem técnicas complexas de cavalaria e navegação ribeirinha, empregadas para fins socioeconômicos e militares. Essas técnicas combinadas com a possibilidade de aliança política possibilitaram que tais grupos resistissem ferozmente à colonização europeia. 
O Chaco foi uma das primeiras regiōes a serem confrontadas com os colonizadores (Metraux, 1946, p. 199). Sua história no século XVI não pode ser separada daquela da conquista do Rio da Prata. Assunção foi fundada em 1536 como base para a exploração do Chaco (Idem, p. 200). O projeto de ocupação e povoamento só foi realizado pelos portugueses no final do século XVIII (Costa, 1999, p. 32; Metraux, 1946, p. 199). Assim, desde muito cedo os povos indígenas dessa região se confrontaram com as forças coloniais, primeiramente espanholas, depois, portuguesas.

Mas o Chaco (especialmente a parte norte, que abrange o pantanal sul-mato-grossense) foi durante séculos uma fronteira importante para os impérios espanhol e português, e a intensa resistência por parte dos índios, especialmente os Guaicuru, mas também os Paiaguá, moldou de maneira peculiar as relações entre colonizador e colonizado, já que nem todos os povos foram subjugados. Aproximaçōes entre a sociedade indígena e a história europeia antiga e medieval passaram a fazer parte dos relatos e do imaginário europeu, pois havia a percepção de que as distâncias não eram tão absolutas. ${ }^{5}$

Em primeiro lugar, devemos ter em mente que na região do Chaco havia um sistema de relações interétnicos complexo.

\section{Figura 1}

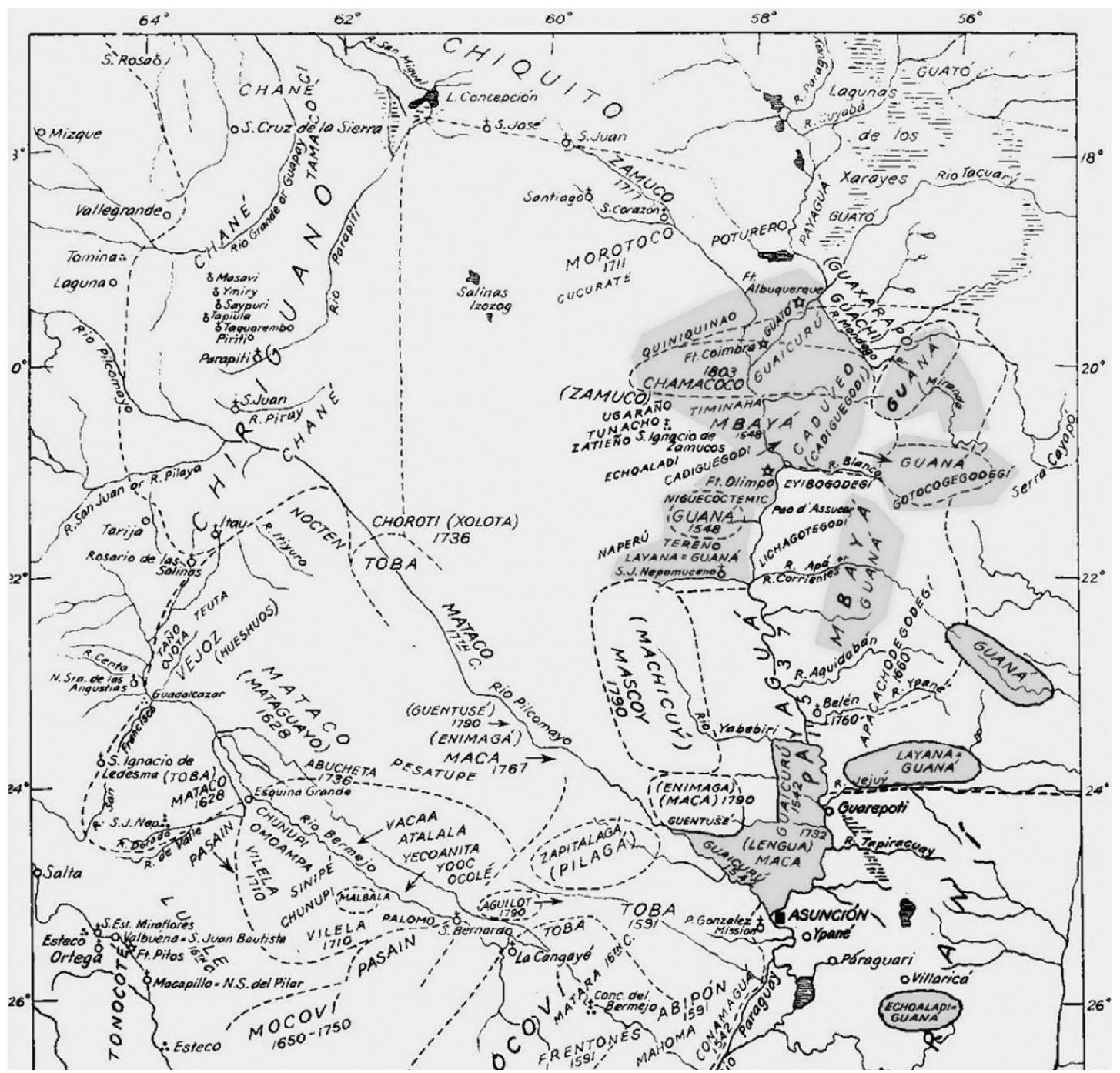

Fonte: Adaptado de Alfred Metraux (1946). 
O croqui (Figura 1) mostra o caráter aparente e parcialmente caótico da localização e do deslocamento dos grupos indígenas nos territórios das duas margens do rio Paraguai. Os Mbayá (Guaicuru) e os Guana ocupavam uma ampla faixa territorial. No período entre 1540 e 1760, aproximadamente, a regiáo foi controlada de forma quase exclusiva pelos índios Guaicuru e Paiaguá. O choque das forças coloniais com as sociedades indígenas deu origem a um sistema de relações interétnicas específico, em que a hegemonia indígena englobava em suas dinâmicas sociais e territoriais, unidades militares e administrativas do colonialismo português e espanhol. As relações de dominação e hierarquia foram retratadas de formas distintas nos diferentes registros históricos, mas, de toda maneira, era recorrente na etnologia brasileira o tema da formação de "classes" ou "hierarquias" em relação aos subgrupos Guana, como os Terena (Cardoso de Oliveira, 1976). Tal especificidade seria tomada então como uma característica dos povos Guaicuru e Guana, traduzida por uma "centralização política e relação de dominação".

Contudo, a especificidade dessas relações não é nem absoluta nem resultado de um sistema cultural endógeno e peculiar, mas sim é consequência do quadro de relações interétnicas, das formas de reciprocidade estabelecidas entres diferentes sociedades indígenas e das contraditórias relaçóes de poder sobretudo entre os Guaicuru e os Guana , e entre estes e os Estados modernos em processo de formação por meio do colonialismo e das respectivas estratégias de resistência, colaboração e dominação.

Estabelecemos como marco de nossa análise o período de 1760 a 1860 , dada a nova situação histórica ali estabelecida, para poder descrever etnograficamente e caracterizar teoricamente essas relações. ${ }^{6}$ Nesse período, encerra-se a hegemonia quase que absoluta dos índios e firma-se uma nova era, em que os Estados modernos avançam suas fronteiras e assentam seus poderes, mas são obrigados a compartilhar e a negociar com os índios a gestão do território. ${ }^{7} \mathrm{O}$ acontecimento fundamental dessa transição histórica (e que fez com que colonizadores e índios tivessem em alguma medida de redefinir suas relações) foi o Tratado de Paz e Amizade de 1791. Trata-se do único documento firmado pelo império português, o que mostra o profundo significado e a importância das relações com os Guaicuru para os portugueses. Do ponto de vista da história indígena e colonial, esse tratado acrescentou um novo componente a uma relação eminentemente dialética, tornando-se símbolo de uma determinada estratégia política que inaugurou o processo temporal de transformação de lógicas de segmentaridade e reciprocidade no universo de luta pelo controle e pela hegemonia territorial dentro de um sistema interétnico.

O tratado em si mesmo pode ser considerado um ato fundador de troca e reciprocidade (cessação dos atos de guerra da parte dos índios em troca de apoio e proteção dos portugueses em relação aos espanhóis) entre sistemas políticos radicalmente diferentes, inaugurando outros circuitos de reciprocidade entre grupos indígenas e Estado. A partir daí, vislumbram-se os dramas de gestão territorial num processo temporal que durou cerca de cem anos e que seria, ele próprio, envolvido por ciclos de reciprocidade e coerção, resistência e colaboração.

Mas é preciso, antes de tudo, estabelecer sob que perspectiva tratamos do conceito de reciprocidade. Assumimos aqui as proposições temporalizadas/ temporalizantes (e por isso mesmo, significantes) delineadas por Pierre Bourdieu (2007) e Victor Turner (1974). As ideias de Bourdieu são importantes exatamente porque vinculam práticas e sentido. Ele aponta a necessidade de romper com a ideia de que a reciprocidade deriva de leis mecânicas provenientes da obrigação de dar, receber e restituir (Bourdieu, 2007 , p. 157). Interessa-nos aqui a discussão em torno da teoria do dom, que parte da pressuposição de uma ruptura entre as lógicas tradicionais, baseadas na obrigação social e moral, e as lógicas modernas, baseadas no interesse e na racionalidade). Dom e contradom se situam-se em ciclos determinados por estruturas (normas, sistemas inconscientes de pensamento, como Bourdieu observa), que supõem etapas articuladas de antemão. A partir disso, devemos reintroduzir a incerteza, a indeterminação, o que significa, em outras palavras, trazer para a análise o conceito de tempo, substituindo a mecânica do modelo pela dialética das estratégias (Idem, p. 159):

Uma análise do intercâmbio de dons, palavras e desafios, para ser verdadeiramente objetiva, 
deve levar em conta o fato de que, longe de desenvolver-se de acordo com um encadeamento mecânico, a série de atos que, apreendidos desde fora e tardiamente, se apresenta como ciclo de reciprocidade supõe una verdadeira criação continua e pode interromper-se em cada um de seus momentos, e que cada um dos atos inaugurais que a constituem correm sempre risco de cair no vazio, de ficar sem resposta, de ser retrospectivamente despojado de seu sentido intencional (não podendo a verdade subjetiva do dom, realizar-se senão no contradom que o consagra como tal (Idem, p. 168).

Nesse sentido, o caráter moral da obrigação é fundamental e, por isso, o próprio tipo de elo social que se caracteriza pela lógica do dom pode ser interrompido; o próprio tempo é componente do significado; uma medida temporal qualifica a obrigação e a diferencia de outras formas de troca. É o intervalo de tempo entre o dom e o contradom que permite entender uma operação como irreversível ao invés de reversível (isto é, obrigada e interessada), de maneira que a temporalidade é que cria uma espécie de "ilusão" de que a obrigação é uma não obrigação e a troca, uma não troca, e sim um laço "social" duradouro e voluntário (Idem, ibidem). Com efeito, o componente de indeterminação delimitado pelo tempo é em si mesmo um elemento de poder. Segundo Bourdieu, manter a incerteza e o desconhecimento das intenções últimas é uma estratégia de poder (Idem, p. 170).

$\mathrm{O}$ essencial da reciprocidade é que ela se cria num contexto em que a probabilidade de sua realização não é dada de forma absoluta pela aplicação de estruturas mecânicas, ao contrário, na sua própria prática existem elementos de indeterminação. A cadeia formada por atos de dar, receber e restituir pode romper-se e reconstituir-se; a obrigação para os agentes e observadores não é absoluta, mas socialmente construída. Além e aquém de um ato moral, a reciprocidade é um ato temporal, que extrai da prática e do tempo seu sentido.

Neste ponto, a teoria da reciprocidade pode ser concatenada com a teoria dos processos sociais de Turner. Baseado na noção de ritual, Turner propóe os conceitos de drama e empreendimento que marcam exatamente como, na realidade, as relações sociais podem oscilar e encadear no tempo não somente relações de cooperação e reciprocidade (materializadas na noção de empreendimento), mas também de conflitos e lutas, expressos pelo conceito de drama. E o mais importante: os acontecimentos ou as fases do drama e dos empreendimentos como processos sociais podem se interpenetrar de maneira que a fase final de um drama pode se transformar em empreendimento e este, por sua vez, pode ou não gerar novos dramas e assim por diante (Turner, 1974).

Assim, a ideia de empreendimento pode ser acionada para circunscrever processos específicos em circuitos de reciprocidade, processos que criam uma comunidade imaginada de obrigaçôes recíprocas e irreversíveis. Tais circuitos explicitam a tendência parcialmente duradoura das trocas e sua mediação por obrigações sociais historicamente construídas. O Tratado de 1791 inaugurou na colônia um processo semelhante, atravessado por dramas de gestão territorial que foram se encadeando e se alternando de forma descontínua com os empreendimentos coloniais e os circuitos de reciprocidade.

Dessa perspectiva, podemos visualizar três ciclos de reciprocidade envolvendo sociedades indígenas e forças coloniais: 1) troca de bens materiais (produtos agrícolas, objetos de metal) e serviços (trabalhos na roça, no transporte fluvial e terrestre, em quartéis e presídios); 2) troca de "bens simbólicos e linguísticos" (especialmente com a disseminação da escrita e do idioma português, com os empreendimentos de catequese e difusão religiosa) e "troca" matrimonial, quando militares, comerciantes e pequenos sitiantes tomavam índias como mulheres; 3) troca de posiçóes de poder na administração (sobretudo no exército e no Estado, pelo "reconhecimento" da lealdade indígena ou de algum serviço prestado.

Analisemos então como o conflito territorial implicava na transformação das lógicas de reciprocidade, num processo em que o resultado final a conquista e a incorporação dos territórios pelo Estado nacional moderno - não era antecipado, mas assegurado pela dialética própria da situação colonial. Esses circuitos não correspondem esquematicamente a períodos históricos, mas, ainda as- 
sim, podemos dizer que depois de 1850 houve uma tendência à intensificação e à conjugação dos três mecanismos de reciprocidade, o que foi revertido a partir da década de $1870 .{ }^{8}$

A lógica de reciprocidade e reconhecimento será substancialmente alterada com a construção das fortificações militares e presídios. No início do século XIX, Ricardo de Almeida Serra, comandante do presídio de Miranda, , pelo, que conviveu com índios Guana e Guaicuru, deixou extensos relatos etnográficos em que reconhecia ter mantido relaçôes íntimas com índios. A partir do momento em que foi estabelecida a unidade militar-prisional do Estado português, foram criados mecanismos de troca de trabalho e bens com os militares. Seria equivocado pensar que essas trocas tenham sido concebidas simplesmente como um mecanismo externo e que se tornaram viáveis apenas em razão do poder coercitivo existente entre os índios Guaicuru e Guana. De fato, trata-se do resultado de estratégias indígenas, de processos de segmentação próprios aos dois grupos indígenas, de suas relaçōes contraditórias e do contexto histórico.

Serra registra, por exemplo, como os Guaicuru exerciam domínio sobre os Guana: eventualmente passavam da cobrança de tributos em espécie ao saque e à violência; os Guana eram considerados "cativos" e sua condição, depreciada, apesar das trocas matrimoniais entre os dois grupos; eram chamados de "portugueses", adjetivo pejorativo para designar índios incompetentes ou incapazes.

O militar também registra como o sistema político dos índios era completamente distinto do sistema europeu: havia inúmeros líderes ou capitães, e o reconhecimento de alguma liderança centralizada dava-se apenas em situações muito específicas. ${ }^{9}$ A mobilidade territorial era intensa, não só dos acampamentos militares dos Guaicuru, mas também dos assentamentos agrícolas dos Guana, motivados por casamentos matrilocais que ignoravam as fronteiras dos tratados entre Portugal e Espanha. A constância tanto de matrimônios interétnicos, que ligavam unidades segmentares dos Guana e dos Guaicuru (o casamento, além de criar alianças, estabelecia tributos por proteção), como da dissolução dessas alianças e reconfiguração dos deslocamentos (acampamento e assentamento) mostra a instabilidade existente nesta área. A configuração segmentar e territorialmente móvel do sistema político indígena foi considerada muito cedo um problema de Estado, e nas cartas trocadas entre Serra e o então governador da capitania, Caetano Pinto de Miranda Montenegro, já era mencionada a necessidade de liquidar esse sistema para assegurar o controle do Estado sobre os territórios e sobre os índios.

A principal estratégia dos portugueses foi tentar constituir relações de reciprocidade com os índios dentro dos preceitos do Tratado de Paz de 1791, além de implementar a política de "dividir para governar", no sentido de tentar desfazer as relações de subordinação e aliança entre Guaicuru e Guana. Esse processo adentra o século XIX, mesmo após Independência e ao longo do período imperial. Em 1838, o Relatório de José Antonio Pimenta Bueno, presidente da província de Mato Grosso, registra o seguinte:

O índio Etacadanne, Cacique dos Cadiueos, a mais importante tribu dos Aycurus, veio com sua mulher, 22 de seus padres, officiaes, e outros vassallos cumprimentar o Governo da Província, e protestar sua amizade e obediência. Vós conheceis, senhores, o quanto ainda hoje interessa-nos a amisade da extença e valente nação dos Uaicurus. Apezar dos poucos recursos que tinha o cofre Provincial foi de mister brindalo; elle voltou satisfeito como informou o commandante militar do Baixo Paraguay, resta que sua índole inconstante não faça cessar as relações que assim abrio-nos. [...] As diversas nações habitantes do Baixo Paraguay, e que já estão no todo alusidas aos nossos hábitos, menos ao de trabalho regular, continuao todas as vezes, que vem a esta capital, a pezar sobre o Cofre Provincial; parece mesmo que julgão ter rigoroso direito de receber auxilio delle, a titulo de ferramenta, vestuário e sustento.

É interessante observar nessa passagem a "inconstância da índole"10 indígena e como os administradores de Estado entendem a percepção dos índios sobre o Estado e os objetos trocados. ${ }^{11} \mathrm{~A}$ inconstância aponta exatamente para o fato de que lealdade e amizade eram estados que poderiam mudar a qualquer momento. Os índios pareciam supor "a obrigatoriedade do Estado em dar brindes", o que mostra, 
na realidade, a similaridade da relação entre os índios e seus próprios chefes. Portanto era factível a ideia de que os índios também aceitavam "ouvir" as palavras do governo da província. Essa relação de troca de brindes por lealdade e solenidade foi registrada de forma sistemática (por exemplo, no relatório de 1840, Estevão Ribeiro de Rezende menciona que os Guaicuru e os Guana se prestavam a úteis serviços, indo se apresentar ao governo em Cuiabá), podendo ter eficácia diversa e relativa. A mesma dinâmica permanece até o final da década pode ser observado no relatório de 1849, do major João de Oliveira: "Com brindes a diversas naçōes de indígenas tem-se despendido no corrente anno financeiro a quantia de $849 \$$ pelo cofre geral, e a quantia de $114 \$ 500$ pelo cofre provincial consistindo esses brindes em ferragens, pannos e medicamentos".

A categoria "brinde", nesse sentido, é fundamental. O brinde é tanto o ato de dar um "presente" como um momento de "saudação", de reconhecimento. Ou seja, esse tipo de troca não só de objetos, mas também, implicitamente, de símbolos, e as ocasiōes em que a troca era efetuada (visitas à sede do governo central, por exemplo) podem ser considerados ritos que, de alguma forma, fortaleciam o próprio Tratado de 1791. Para os índios, o governo tinha a obrigação de fornecer brindes; o Estado acreditava que os índios deveriam ser leais e obedientes a ele. Mas, evidentemente, tal reciprocidade podia ser rompida por qualquer uma das parte, pois não era algo absolutamente garantido, ainda que constituído, como pode ser observado sistematicamente entre as décadas de 1830 e 1840 . Isso mostra que o poder coercitivo do Estado não foi plenamente eficiente até aquele momento. Num certo sentido, a chamada "inconstância do caráter indígena" expressa exatamente o esvaziamento histórico da autoridade política do Estado moderno sob a forma do Império. Os índios podiam romper a lógica da reciprocidade e abandonar os empreendimentos estatais, assim como podiam abandonar suas próprias lideranças. Naquele momento, sua autonomia e hegemonia sobre o território permitiam-lhes estender suas próprias lógicas para a relação com o Estado. Em outras palavras, mantinham-se as trocas, mas recusava-se o poder do Estado sobre a organização interna do grupo, da mesma forma que a autoridade indígena centralizada era esvaziava por meio de processos de segmentação permanentes. Com efeito, isso era um problema para o Estado moderno.

Figura 2

Modelo Gerativo de Reciprocidade Temporalizada

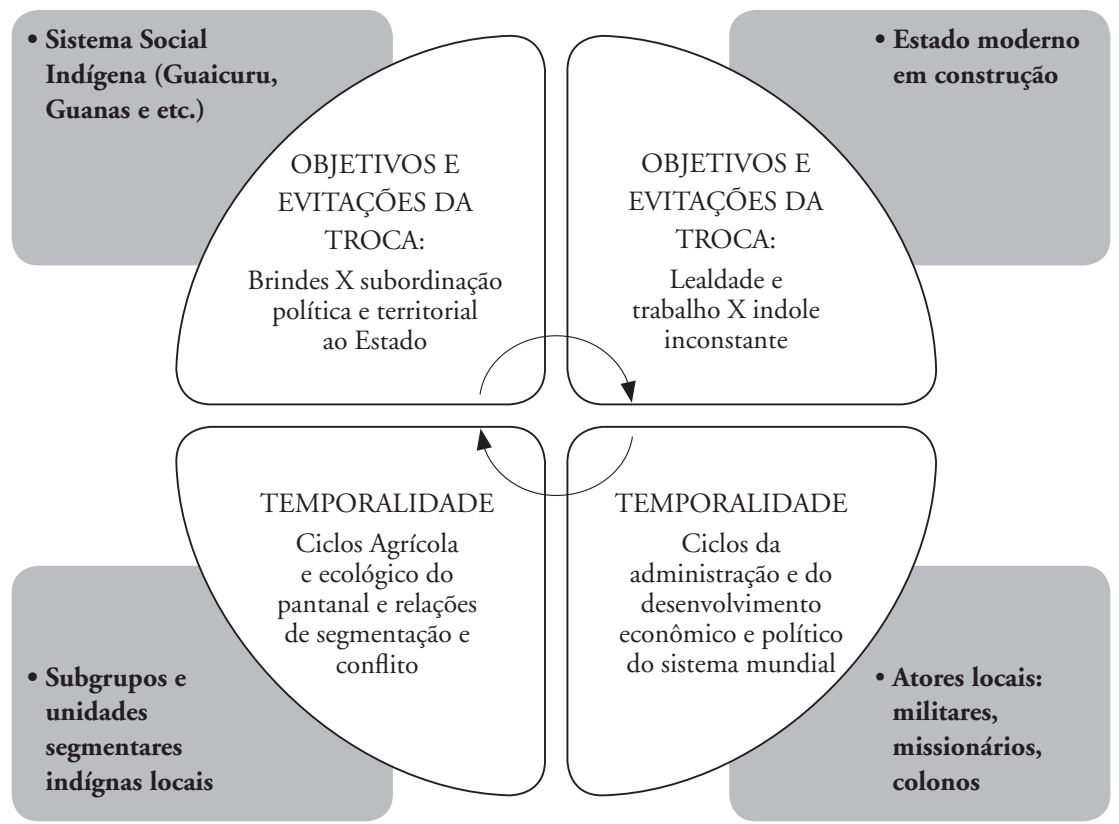


A Figura 2 esboça um modelo de processo gerativo de troca que representa os ciclos de reciprocidade. Na verdade, o que ocorria era o confronto, a articulação de objetivos/evitações e a temporalidade, que operavam em escalas distintas, mas que adquiriam sentido por meio de práticas compartilhadas. É interessante observar que os objetos trocados sob a forma de brinde, como já destacamos, faziam parte do universo agrícola e ecológico do pantanal e das formas de organização social, nas quais os Guaicuru cumpriam o papel de redistribuição de ferramentas e tecnologias obtidas nas instâncias do governo provincial. Ao mesmo tempo, evitavam uma subordinação total ao Estado, e por isso não aceitavam serem incorporados como força de trabalho tal como o Estado esperava. A temporalidade específica do sistema social do Chaco/Pantanal confrontava-se e articulava-se com a temporalidade do sistema mundial da produção de mercadorias e da incorporação de populaçôes locais no mercado. A indeterminação das trocas e das obrigaçôes era o que possibilitava a inter-relação entre os sistemas, apesar dos contrastes e dos conflitos latentes. Isso fica explícito na forma como as lideranças políticas se manifestavam na prática.

O relativo esvaziamento da autoridade do chefe na cultura indígena, possibilitava que qualquer autoridade exterior pudesse ser também colocada numa condição análoga, e por isso pudesse ser ela própria interiorizada. Ou seja, se a ideia de que os índios exteriorizavam sua relação com a autoridade é verdadeira, isso implica que eles também poderiam interiorizar "chefes" não indígenas, cujo poder também poderia ser esvaziado com base no mesmo mecanismo e dentro da mesma "lógica". Isso não era o resultado apenas da negação da autoridade do chefe, mas sim das características da organização social e da segmentação dos grupos, que não reconheciam a autoridade permanente de líderes que cumprissem um papel de centralização, mas que eram regidos por líderes de unidades segmentares nos "bairro-cacicados" Guana ou nos acampamentos Guaicuru. A mesma instabilidade que marcava o sistema político indígena foi transferida para o Estado que, consequentemente, não conseguia estabelecer sua hegemonia. Para isso foi preciso transformar o sistema, o que demandava tempo. Tempo, nesse caso, era a possibilidade de alcançar certas condições, realizar processos e circulação de bens materiais e simbólicos, constituir exército, cumprir prioridades. Assim, o tipo de relação estabelecida com Estado era muito similar à existente entre os índios e seus próprios "chefes". Mas daí também a contradição do Estado e sua necessidade de intervenção na organização social indígena. E a necessidade de se construir uma obrigação duradoura a ser vivida pelos outros na sua temporalidade, tanto por parte dos índios como do Estado, era em si mesma um componente do poder dos ciclos de reciprocidade. Mais do que assumir a obrigação como permanente, pretendia-se induzir os outros a isso. Todavia, o caráter dialético fazia com que os índios retribuíssem sistematicamente com "serviços" (inclusive de segurança da fronteira, o que era percebido pelo Império como ato de lealdade para com sua soberania) o dom recebido sob a forma de "brinde". Em contrapartida, o Estado também foi obrigado a prolongar tais obrigaçôes, revelando a parcialidade e as contradiçôes de seu próprio controle.

Mas, especialmente a partir de 1850, essas trocas não ficaram restritas a brindes. Iniciam-se nesse momento os experimentos de constituição de aldeamentos geridos por missionários e, com eles, o processo de catequese e civilização. ${ }^{12}$ Aprofundam-se os mecanismos para as trocas de "palavras", em que se incentiva a transição da oralidade à escrita $\mathrm{e}$ a introdução de outros signos culturais. Isso resultou uma série de analogias estabelecidas pelos índios - a utilização do termo "padre" para designar xamã, por exemplo; termos registrados por Taunay durante a Guerra do Paraguai e que continuaram em uso até a primeira metade do século XX. Tratavam-se de expressões estratégicas para designar poder, autoridade (política e mágico-religiosa ou pertencimento. O fundamental é que essas trocas não eram diádicas, envolviam um leque extremamente amplo e desterritorializado de atores dos dois lados do rio Paraguai e ao sul do Mato Grosso.

Assim, as relaçôes de reciprocidade estenderam-se ao longo do século XIX sob formas de aliança e de processos de troca específicos, em uma situação histórica geral de compartilhamento da hegemonia sobre amplos territórios e relativa autonomia política. Tais relaçôes não excluíam atos 
de resistência cotidiana (deserção, roubo, saque e as chamadas "correrias", isto é, ataques armados contra fazendas e unidades militares), ao contrário, sua permanência alimentava a ideia da "inconstância do caráter indígena”. A manipulação estratégica das relações de reciprocidade por parte das unidades segmentares era traduzida de forma naturalista na interpretação do Estado, numa teoria sobre o caráter indígena, que, antes de se reduzir a uma mera expressão de etnocentrismo, revelava uma visão peculiar sobre a historicidade da relação colonial. Por outro lado, o Estado tentava estender seu poder coercitivo, seja sob a forma da dominação racional-legal, seja pelo uso da violência com o envio de expedições de bandeirantes para o interior do território, denominadas Bandeiras. Assim, as relaçôes de reciprocidade não eram excludentes, ao contrário, elas viabilizavam formas de colaboração cotidiana que incluíam tanto a resistência, como a própria dominação. Ou seja, os empreendimentos coloniais podiam se transformar em dramas sociais (que tinham como componente fundamental o controle do território), e do poder não coercitivo da troca podia se originar a repressão.

A Guerra do Paraguai possibilitou a conversão da relação de reciprocidade em relação de coerção, como formas predominantes do sistema interétnico constituído na região das bacias do rio Paraguai. Isso nos obriga a entender a reciprocidade como um processo temporal, mediado, nesse caso, por dramas de gestão territorial. Os conflitos que tinham levado ao Tratado de Paz e Amizade diziam respeito à gestão territorial: os índios firmaram o Tratado para poder se abrigar e se proteger do avanço espanhol; os portugueses, para conter o avanço espanhol em terras que a Espanha e depois o Paraguai reivindicavam como suas. Várias situações sociais e processos de cooperação, conflito e reatamento de relaçôes foram ali estabelecidos. Mas a Guerra do Paraguai provocou uma mudança fundamental: um dos atores desaparece do cenário e, portanto, a ameaça "externa" de um Estado nacional moderno cessa. A condição geopolítica, que proporcionara a estruturação das relações de reciprocidade com os índios, deixara de existir.

Com o fim da guerra, os índios começam a ser cada vez mais reprimidos. Processos de expropriação territorial alastram-se por meio de força armada ou de instrumentos jurídicos para a titulação de propriedades. Os índios perdem seu espaço no governo provincial, a ver pelos relatórios do período pós-guerra quase sempre omissos em relação a eles. A relação de reciprocidade transforma-se em coerção, o que constitui um processo temporal, pois a reciprocidade ocorre em meio a dramas sociais em que os atores envolvidos podem mudar suas estratégias ou interesses, os quais, por sua vez, dependem de mudanças mais gerais do sistema. O término da "reciprocidade negativa" entre Brasil e Paraguai não somente tornou dispensável o grau de "reciprocidade" anteriormente estabelecido, como foi acompanhado por outros fatores importantes, como a incorporação das terras da região sul de Mato Grosso, da bacia do Prata e do Paraguai pelo capital monopolista exportador favorecendo a formação de grandes fazendas. Isso permitiu que anos de reciprocidade fossem transformados a partir de então em atos de repressão. Ou seja, a obrigação de dar "brindes" foi quebrada, mudando substancialmente as formas do exercício de poder. Mas, do ponto de vista histórico, mesmo um poder não coercitivo pode estar associado a formas de dominação, no sentido de que prepara condiçôes que, somadas a outras no decorrer do tempo, adquirem sentido.

Enfim nem a reciprocidade, nem a segmentação são lógicas constituídas à margem da história e das interações com outros sistemas políticos. As relaçōes de parentesco que organizavam as sociedades indígenas e a constituição de um domínio "político" dentro dessas sociedades permitiram a incorporação de diferentes formas de poder e de diferentes sistemas políticos. Vale lembrar que o ponto final do processo foi, para grande parte dos povos do antigo sistema interétnico, a inserção dos índios na economia capitalista, como força de trabalho assalariada nos latifúndios regionais. Desde o início já existia essa intenção por parte dos colonizadores, mas ela apenas se efetiva a partir do início do século XX, transformando-se num amplo regime de recrutamento de mão de obra a partir da década de 1980 , com a implantação da agroindústria canavieira.

Considerar essas lógicas como processos temporais significa dizer que elas se transformam internamente, não somente do ponto de vista dos ciclos 
(substituição de lideranças, mudança nas alianças entre grupos), mas também da variação concernente ao exercício do poder e aos grupos hegemônicos. O Estado, portanto, também não pode ser encarado como uma entidade lógica e a-histórica; é preciso perceber tanto os ciclos de sucessão, como a geração de formas peculiares de poder estatal em decorrência do uso de diferentes estratégias práticas não codificadas juridicamente. É exatamente isto que consiste a dialética da situação colonial: de um lado, o fato de o Estado moderno empregar formas de poder não coercitivo para assegurar a dominação; de outro, a aliança entre unidades segmentares indígenas e unidades coloniais que permitiram a certos grupos indígenas exercerem poder coercitivo sobre outros; e ainda, o paradoxo de que esse sistema obstruiu durante séculos a própria expansão colonial e a consolidação do Estado moderno.

O caso do sistema do Chaco/Pantanal é mais do que um exemplo da forma singular das dinâmicas indígenas sul-americanas; pode servir como base para uma teoria sobre o caráter aberto e dialético da constituição dos sistemas interétnicos por meio da confrontação colonial e seu estudo comparativo. Mas isso é uma tarefa que ainda está por ser realizada.

\section{Considerações finais}

Podemos agora retomar a alguns dos problemas etnológicos e teóricos apresentados inicialmente. Conceitos clássicos como segmentação e reciprocidade podem auxiliar muito na compreensão das sociedades indígenas do ponto de vista da antropologia de processos históricos. Mas é preciso evitar alguns equívocos. O primeiro recai sobre a separação "tipo-lógica", que opõe sistemas estatais a sistemas sem Estado ou poder coercitivo a poder não coercitivo, como se cada um correspondesse rigidamente a formas de sociedades (modernas no caso dos primeiros, tradicionais/indígenas, no caso dos segundos).

O estudo de uma "variação" mostrou exatamente as contradiçôes e os limites de um modelo teórico construído sobre o pressuposto de que a análise e a explicação dos problemas etnológicos residem em estruturas cognitivas ou normativas. A cisão da "reciprocidade" que caracterizaria a relação com os "chefes" se verifica também de forma instrumental na relação com o Estado. Isso dialeticamente permitiu que o Estado fosse um componente da organização social indígena, interno, não externo (Bourdieu, 2007; Oliveira Filho, 1988). Mas essa cisão, sob forma de atos de resistência cotidiana, não foi absoluta, assim como não era também a cisão das formas de reciprocidade com os chefes indígenas. ${ }^{13}$ Os índios eram obrigados a manter alguma forma de reciprocidade, assim como próprio Estado, não porque simplesmente quisessem, não porque existissem "sistemas de pensamento" homogêneos que orientavam nesse sentido, mas porque a situação histórica e as condiçôes práticas de sua confrontação induziram acidentalmente a essa situação.

Dessa maneira, podemos ver que na realidade um aspecto fundamental da dialética colonial é como o Estado moderno, para se constituir, precisou se articular com um sistema não estatal, hegemônico sobre os territórios do Chaco/Pantanal e controlado na maior parte do tempo pelos cavaleiros Guaicuru. O Estado moderno, pois, surge do "não Estado indígena" tanto pelo poder coercitivo, como pelo manejo estratégico de longo prazo de formas de poder não coercitivo baseadas em lógicas de reciprocidade e em contradiçôes internas ao sistema social indígena. Outro aspecto dessa dialética é que, ao mesmo tempo, essa articulação com as forças coloniais possibilitou certa "igualdade" entre o grupo indígena dominante - os Guaicuru, que ao firmarem o Tratado de Paz, adquiriram o estatuto de uma nação soberana - e os colonizadores. Além disso, a relação de "igualdade ou equivalência do sistema interétnico" implicava uma profunda desigualdade em relação a outras sociedades indígenas (como os Guana, os Guarani e os Chamacoco), povos considerados cativos pelos Guaicuru. ${ }^{14} \mathrm{Os}$ portugueses tentavam manipular as contradições das sociedades indígenas em seu favor, oferecendo uma relação mais "igualitária” aos Guana. Contraditoriamente, durante muito tempo essa estratégia não foi eficiente, e os índios conseguiram manter sua hegemonia, ou no período aqui considerado, ao menos evitar que o Estado alcançasse plenamente 
seus objetivos obrigando-os a uma forma de gestão compartilhada do território.

A ideia da "inconstância indígena" acionada pelos agentes de Estado durante o século XIX expressa, assim, uma situação histórica encerrada com a guerra do Paraguai. A partir de então, reciprocidade se converteu em coerção. $\mathrm{O}$ que não implica dizer que não existissem outros tipos de relaçôes estabelecidas por grupos e lideranças, mas sim que ela cedeu um lugar predominante para outras formas de exercício do poder. O período posterior de escravidão nas fazendas e da formação de reservas indígenas (já no final do século XIX e início do XX) mostraria a complexidade dessas formas de poder.

Nesse sentido, devemos estabelecer outras abordagens teóricas, ou um projeto de uma nova antropologia política e histórica que retome a discussão acerca do poder, construindo problemas que possam dar margem não somente a novos dados etnográficos, mas a novas interpretaçôes de antigos dados, e que possibilite análises comparativas numa escala mais ampla (Wolf, 2009). O primeiro problema diz respeito à gênese do Estado moderno, sucessivamente traduzido na antropologia neoevolucionista, estrutural-funcionalista e estruturalista como de ordem lógico-arqueológica. Ou o Estado moderno é fruto de um processo de longuíssima duração e se explica pela evolução, ou se constata a coexistência de sistemas políticos distintos, sem qualquer comunicação e condicionamento mútuo, ou, ainda, ele fruto de determinada estrutura de pensamento, sendo sua ausência explicada somente pela existência de um sistema de pensamento que o negue. Como já demonstramos, essas respostas levam ao impasse quando defrontadas ao fato histórico de que o Estado moderno nas Américas surge das relações de aliança, coerção e reciprocidade que estabeleceu com sistemas sociais distintos dele próprio; que ele surge exatamente e por meio de um sistema que se opunha a ele em termos históricos reais. A ideia de ausência de conflito nos sistemas não estatais transforma o problema histórico da formação dos Estados no cerne da colonização e da conquista da América num problema ontológico da passagem de um estado de natureza a um estado de cultura, como elemento universal e a-histórico ou de coexistência de sistemas políticos logicamente heterogêneos, mas funcionalmente homogêneos.

É preciso romper com esse tipo de abordagem. A antropologia política não pode ser senão uma antropologia histórica do poder, ou seja, da luta e da guerra e das formas de segmentação e reciprocidade. O problema da gênese do Estado moderno não poder ser senão o problema da explicação de como histórias locais e diversificadas de confrontação entre forças coloniais e sociais diversas chegaram a ser o que são hoje não por desdobramento lógico, nem por alguma inexorabilidade histórica, mas como o resultado de uma confrontação que ainda permanece em curso. O problema da gênese do Estado moderno é, em seu reverso etnográfico, o problema da etnogênese dos grupos hoje existentes, porque as diferenças sociais e culturais são fruto de um processo histórico que pode ser determinado e analisado e no qual as próprias sociedades indígenas reais se definiram (em termos territoriais, de organização social e frequentemente de etnônimo). Num certo sentido, todos os grupos passaram por algum tipo de etnogênese, já que se confrontaram (e se confrontam) com o colonialismo. Por fim, um último problema-objeto dessa antropologia política são as diferentes e contraditórias formas de poder geradas pela sociogênese do Estado e pela etnogênese, os diferentes fundamentos sociológicos, culturais e históricos da hegemonia e a desigualdade entre grupos nas suas relações contemporâneas. Essas formas de poder, que vão desde a escala interpessoal ou diádica até aquilo que Eric Wolf denominou "poder tático ou estrutural", trazem à tona em termos processuais os dois problemas anteriores, pois toda relação e forma de poder tem, ela própria, sua história e sua dinâmica.

As reflexões aqui apresentadas não são obviamente exaustivas, mas delineiam uma analítica alternativa, uma antropologia política e histórica. Política não só porque toma como objeto a políti$\mathrm{ca}$, mas porque reflexivamente toma as condiçōes políticas como base da constituição de sua reflexão; historiciza, no sentido de contextualizar, significar e mostrar continuidades e rupturas das relações sociais. Ao mesmo tempo explicita que a própria narrativa antropológica está politicamente situada dentro dos problemas podendo ou legitimar ou 
questionar a legitimidade de poderes e atores que toma como objeto. É esse o teor da proposta teórica e etnológica de antropologia aqui apresentada.

\section{Notas}

1 Levando em conta aqui a interpretação de Barth (1959) e sua apreciação crítica da teoria da linhagem, e fazemos também uma interpretação da formulação de Evans-Pritchard em Os Nuer, em que o autor apresenta sua tese sobre o princípio de fissão e fusão na análise dos sistemas políticos africanos.

2 Tanto que quando a etnologia trata dessas questões, normalmente se aborda do ponto de vista da longuíssima duração, numa escala temporal arqueológica, buscando ver o surgimento dos Impérios Inca etc., mas não se considera a formação dos Estados nacionais modernos, e portanto o colonialismo moderno, como um tema de antropologia política ou mesmo de “origem" do Estado.

3 A esse respeito, temos como referencia os estudos sobre resistência camponesa de James Scott (1986), os estudos sobre faccionalismo e antropologia política de Marc Swartz e Ralph Nicholas (1968) e as formulações de João Pacheco de Oliveira Filho (1988a e b) e Victor Turner (1974). A ideia de resistência cotidiana, pela própria definição de Scott, implica num pragmatismo e acomodação a condições materiais e objetivas para que os grupos subalternizados possam sobreviver dentro de um sistema de dominação. Por outro lado, os trabalhos de Swartz e Nicholas teorizam sobre a "natureza" dos sistemas políticos emergentes depois de processos de mudança social de larga escala, especialmente nos novos Estados, em que as antigas sociedades "tradicionais ou tribais" tinham perdido sua autonomia política e territorial e estavam agora integradas em lógicas políticas do Estado nacional moderno, sendo condicionadas pela competição por recursos na política local, em prefeituras, parlamentos e outros órgãos da administração.

4 O topônimo Chaco (do Qêchua, Chacu) indicava inicialmente a província de Tucúman, passando a designar posteriormente todo o território a leste dela, numa extensão de 700 mil quilômetros, abrangendo territórios da Bolívia, Argentina, Paraguai e Brasil (ver Cunha, 1992, p. 457).

5 Isso é um tópico importante para compreender a especificidade das relações dos colonizadores com os índios. A descrição das relações entre os Guaicuru e os
Guana por parte de Sanches Labrador e Felix Azara, por exemplo, evocam o conceito de "vassalagem" existente na Europa medieval, ou ainda evocam a imagem dos povos guerreiros da antiguidade para qualificar os Guaicuru.

6 Utilizamos aqui a noção de situação histórica tal como desenvolvida por João Pacheco de Oliveira em seu livro $O$ nosso governo, basicamente como um instrumento que correlaciona balanceamento de forças/ equilíbrio de poder a configurações territoriais.

7 Para uma análise mais detalhada desse processo de transformação, ver Ferreira (2007).

8 Com o término da guerra do Paraguai, configurou-se outra situação histórica, marcada pelo movimento de expansão da fronteira agrícola e acumulação primitiva de capital na província de Mato Grosso, com a consequente expropriação das terras de diversas sociedades indígenas.

9 Para uma análise mais detalhada a esse respeito, ver Ferreira (2007). As fontes mostram que havia uma média de um capitão para cada 45 pessoas.

10 A ideia de índole é importante porque naturaliza um comportamento que é, na realidade, condicionado por estratégias, formas de organização social e cultural.

11 Ferramentas, vestuário e sustento são objetos com funções e conteúdos simbólicos diferentes. Os Guaicuru entendiam o trabalho agrícola como uma atividade de cativos e escravos. Assim, as ferramentas só faziam sentido para os agricultores, Guana e outros povos, sendo que, do ponto de vista imperial, esse tipo de agricultura não era considerada "trabalho", justamente porque trabalho devia ser uma atividade dirigida e subordinada aos objetivos produtivos do Estado. Sustento e vestimentas figuram como dádivas, associadas à honra que os Guaicuru se atribuíam e ao papel de redistribuição de dons que os líderes cumpriam nas unidades segmentares Guana.

12 Segundo o capitão de fragata Augusto Leverger, em seu relatório de 1851: "No districto do Baixo Paraguay, diversas tribus, particularmente das nações Guaná e Guaicurú, existem aldeadas com hum tal qual principio de civilização, e entretem connosco relações mais ou menos estreitas. Releva fazer muito especial menção da grande aldeia dos Kinikinaos que habitao o lugar chamado Mato Grande, distante três legoas de Albuquerque. Quando a visitei há cinco annos, a sua população excedia de 700 almas. A civilização destes índios, que teve começo há mais de 20 annos (continua a progredir, e recentemente não pequeno impulso recebeo do zeloso missionário Capuchinho Frei Mariano de 
Bagnaia, vindo para esta província em virtude do aviso do Ministério do Império de 12 de maio 1847. Há pouco erigiu na aldea huma Capella sob a invocação de Nossa Senhora do Bom Conselho e instalou huma escola em que 30 meninos recebem o ensino primário. Espero, e he muito para dezejar, que sejão coroadas de igual sucesso as diligencias de Frei Antonio de Molinetto, collega daquelle Missionário, para a catechese dos Terenas nas imediaçóes de Miranda, para cujo fim tem dado o Governo todas as providencias que lhe parecerão convenientes, ou the forão pedidas" (pp. 44-45).

13 No espaço restrito deste artigo não é possível desenvolver uma reflexão aprofundada a esse respeito, mas a ideia de Clastres é de que a poliginia implicava numa concentração de mulheres pelos chefes que não era retribuída, quebrando assim a lógica de reciprocidade. Entretanto, isso supõe uma estabilidade dos matrimônios e que as trocas sejam sempre simétricas, esquecendo que dentro de certos contextos era possível compensar a reciprocidade por meio de algum tipo de "equivalente geral" introduzido nas trocas e que a própria chefia era submetida a conflitos de sucessão que implicavam em redistribuição de mulheres dentro de uma mesma geração e entre elas.

14 É nesse sentido que construímos nossa análise das relações de dominação, resistência e colaboração entre os índios Terena e o Estado nacional, mostrando como dominaçôes horizontais (formas de poder coercitivo entre grupos e facções indígenas) e verticais (de grupos dominantes sobre as sociedades indígenas por formas de poder não coercitivo, por relações reciprocidade).

\section{BIBLIOGRAFIA}

BARTH, Fredrik. (1959), "Segmentary oposition and the theory of games: a study of Pathan organization". The Journal of The Royal Anthropological Institute of Great Britain and Ireland, 89: pp. 5-21.

. (1967), "Economic spheres in Dafur", in Raymond Firth (org.), Themes in economic anthropology, Londres, Tavistock. pp 149-174 . (1984), "Problems of conceptualizing cultural pluralism, with illustrations from Somar, Oman, in D. Maybury-Lewis, The prospects for plural societies, Washington, DC, American Ethnological Society.
(2000A), "Os grupos étnicos e suas fronteiras", in Tomke Lask (org.). O guru, o iniciador e outras variaçôes antropológicas, Rio de Janeiro, Contracapa, pp. 25-67.

(2000B), "A análise da cultura nas sociedades complexas", in Tomke Lask (org.). $O$ guru, o iniciador e outras variaçóes antropológicas, Rio de Janeiro, Contracapa, pp. 107-140.

(2000C), "Por um maior naturalismo na conceptualização das sociedades", in Tomke Lask (org.). O guru, o iniciador e outras variaçôes antropológicas, Rio de Janeiro, Contracapa, pp. 167-186.

BOURDIEU, Pierre. (2007), El sentido práctico. Buenos Aires, Siglo XXI.

CARDOSO DE OLIVEIRA, Roberto. (1976), Do indio ao bugre: o processo de assimilação dos Terena. 2 ed. revista. Rio de Janeiro, Francisco Alves.

(1997), Sobre o pensamento antropológico. Rio de Janeiro, Tempo Brasileiro.

CASANOVA, Pablo González. (2002), Exploração, colonialismo e luta pela democracia na América Latina. Petrópolis, Vozes.

CLASTRES, Pierre. (2003), A sociedade contra o Estado: pesquisas de antropologia politica. São Paulo, Cosac \& Naify.

COSTA, Maria de Fátima. (1999), História de um país inexistente: o Pantanal entre os séculos XVI e XVIII. São Paulo, Estação Liberdade/Kosmos.

CUNHA, Manuela Carneiro da (org.). (1992), História dos indios no Brasil. São Paulo, Companhia das Letras.

FABIAN, Johannes. (1983), Time and the other: how anthropology makes its objects. Nova York, Columbia University Press.

FERREIRA, Andrey Cordeiro. (2007), Tutela e resistencia indigena: etnografia e história das relaçôes de poder entre os Terena e o Estado brasileiro. Rio de Janeiro, tese de doutorado, PPGAS-Museu Nacional/UFRJ.

FORTES, Meyer \& EVANS-PRITCHARD, E. (1940), African political systems. Oxford, Oxford University Press.

METRAUX, Alfred. (1946), "Ethnography of The Chaco", in Julian Steward (org.), Handbook of South American Indians. Washington, DC, 
United States Government Printing Office, vol. 1.

NICHOLAS, Ralph W. (1968), Segmentary Factional Political Systems, in Swartz e Turner, Local-level politics.

OLIVEIRA FILHO, João Pacheco de. (1988), O nosso governo: os Ticuna e o regime tutelar. São Paulo, Marco Zero. (1998A), "Uma etnologia dos 'índios misturados'? Situação colonial, territorialização e fluxos culturais". Mana, 4 (1), pp. 47-77.

(ORG.). (1998B), Indigenismo e territorialização: poderes, rotinas e saberes coloniais no Brasil contemporâneo. Rio de Janeiro, Contracapa.

RADCLIFFE-BROWN, A. R. (1940), "Preface", in Meyer Fortes e E. Evans-Pritchard, African political systems. Oxford, Oxford University Press.

RELATÓRIOS DOS PRESIDENTES DE PROVÍNCIA. CENTER FOR RESEARCH LIBRARIES, disponível em <http://www.crl.edu/ content>. [Relatório de 1837, de José Antonio Pimenta Bueno; Relatório de 1838 de José Antonio Pimenta Bueno; Relatório de 1840 de Estevão Ribeiro de Rezende; Relatório de 1849, de João de Oliveira; Relatório de 1851, de Fragata Augusto Leverger.]

SCOTT, James. (1986), "Everyday forms of peasant resistance". The Journal of Peasant Studies, 13 (2): pp. 6-31.

SWARTZ, Marc J.; TURNER, Victor \& ARTHUR, Tuden. (1966), Political anthropology. Chicago, Aldine Publishing Company.

SWARTZ, Marc J. (1968), Local level politics: social and cultural perspectives. Chicago, Aldine $\mathrm{Pu}-$ blishing Company.

TURNER, Victor. (1974), Dramas, fields and metaphors: symbolic action in human society. Ithaca, Cornell University Press.

WEBER, Max. (1999), Economia e sociedade. 3 ed. Brasília, Editora da UnB, vol. 1.

WOLF, Eric R. (2009), A Europa e os povos sem história. São Paulo, Edusp. 


\section{DIALÉTICAS COLONIAIS: A CONSTRUÇÃO DO ESTADO E AS TRANSFORMAÇÓES DA ORGANIZAÇÃO SOCIAL INDÍGENA SUL-AMERICANA}

\section{Andrey Cordeiro Ferreira}

Palavras-chave: Colonialismo; Reciprocidade; Segmentaridade; Processos políticos.

O presente artigo tem como objetivo apresentar hipóteses sobre as relaçōes dialéticas entre dois processos: o de construção do Estado nacional moderno no Brasil e o das transformações da organização social indígena sul-americana. Partindo de uma situação etnográfica específica índios do Chaco/Pantanal brasileiro -, apresentamos hipóteses críticas alternativas às da etnologia evolucinista, estruturalista e estrutural-funcionalista sobre a relação da origem do Estado moderno. Enfatizamos a maneira pela qual as lógicas de segmentação e reciprocidade, descritas na etnologia, foram integradas por dialéticas coloniais, envolvendo processos de dominação e resistência política.

\section{COLONIAL DIALECTICS: THE MAKING OF STATE AND THE TRANSFORMATION OF SOUTH AMERICAN INDIGENOUS PEOPLES ORGANIZATION}

\section{Andrey Cordeiro Ferreira}

Keywords: Colonialism; Reciprocity; Segmentarity; Political processes.

This article has as its objective to put forward some hypotheses about the dialectical relationships between two social processes. On the one hand, the nationbuilding process in Brazil and on the another hand the transformation of the South American indigenous social organizations. Our starting point is a specific ethnographic background, the Chaco/ Pantanal (floodable swamps in central Brazil). We make a critique of some evolutionist and structuralist views on state building and indigenous peoples leadership, demonstrating how the segmentary organization and the reciprocity logic are interwoven into colonial social-historical dialectics.

\section{DIALECTIQUE COLONIALE: CONSTRUCTION DE L'ÉTAT ET LA TRANSFORMATION DES ORGANISATIONS SOCIALES INDIGËNES SUD-AMÉRICAINES}

\section{Andrey Cordeiro Ferreira}

Mots-clés: Colonialisme; Réciprocité; Segmentarité; Processus politiques.

Cet article a pour objectif de présenter certaines hypothèses sur les rapports dialectiques entre deux processus sociaux : celui de la construction de l'État national moderne au Brésil et celui des transformations de l'organisation sociale indigène sud-américaine. À partir d'une situation ethnographique spécifique - les indiens du Chaco/Pantanal brésilien nous présentons des hypothèses critiques alternatives à celles de l'ethnologie évolutionniste, structuraliste et structuraliste/ fonctionnelle sur l'origine de l'État moderne. Nous mettons en avant la façon par laquelle les logiques de segmentation et de réciprocité - décrites par l'ethnologie - ont été intégrées par les dialectiques coloniales, englobant des processus de domination et de résistance politique. 